\title{
Gender and life cycle approach in social protection to improve environmental managemet for urban sustainability
}

\author{
Donna Asteria ${ }^{1, *}, B^{*}$ Budidarmono ${ }^{2}$, Retty Dwi Handayani ${ }^{3}$, Dyah Utari $^{4}$, and Elok Faiqotul \\ Mutia $^{5}$ \\ ${ }^{1}$ Communication Department, Faculty of Social and Political Science, Universitas Indonesia, Depok, \\ Indonesia \\ ${ }^{2}$ Faculty Law, Universitas Indonesia, Depok, Indonesia \\ ${ }^{3}$ School of Strategic and Global Studies, Universitas Indonesia, Salemba, Indonesia \\ ${ }^{4}$ Faculty of Health Science, Universitas Pembangunan Nasional "Veteran", Jakarta \\ ${ }^{5}$ School of Environmental Science, Universitas Indonesia, Salemba, Indonesia
}

\begin{abstract}
The purpose of this study is to describe the environmental management strategy using gender and life cycle approach through social protection activities. Social protection activities are important in urban areas that undergo a transformation post-disaster in their urban system, related to the life cycle of people in the city and the framework of urban sustainability. The social protection will also increase people's access to environmental resouces so that people are able to participate in environmental management. Vulnerabilities and risks due to environmental degradation of cities require social protection efforts for the community, especially women includes household (family) to strenghten human skill in life cycle. The research used the AHP (Analytical Hierarchy Process) method. This method utilized the expert judgments in the form of options that must be done by the stakeholders. The results of this study show that social protection with gender mainstreaming will increase the ability of citizens to participate and strengthen communities in managing the urban environment that achieve social justice for the community for the sustainability of the city. The contribution of this study can be an alternative strategy for environmental management in the city and more gender responsive policy making.
\end{abstract}

\section{Introduction}

To achieve sustainable development goals in urban areas, the life cycle approach is very important to be used as an approach in urban environmental management, especially environmental conservation after disasters in urban areas. Disasters due to the impacts of climate change cause social, economic and environmental problems that are closely relatedto people's welfare. This condition can reduce the city's resilience to achieve sustainability. The conditions that cause environmental degradation are closely related to

\footnotetext{
*Corresponding author: donna@ui.ac.id
} 
social and economic situations, both poverty, unsustainable patterns of production and consumption, injustice, failure to manage the environment and various complexities of problems in development. To achieve sustainability requires a life cycle approach in shaping community capabilities with the participation of all actors in the community through social protection. In order to overcome urban problems, poverty and ecology degradation, social protection as solution to achieve sustainability of the city.

Social protection is an effort to improve people's ability to empower themselves from the risk and vulnerability situations caused by ecological disasters occurring as a result of climate change in the city. Social protection with a community-based approach provides an opportunity for citizens, especially women, to improve their ability to achieve environmental resilience. The social protection will also increase people's access to environmental resouces so that people are able to participate in environmental management. Vulnerabilities and risks due to environmental degradation of cities require social protection efforts for the community, especially women includes household (family) to strenghten human skill in life cycle. Environmental disaster and environmental conflicts occurring in cities often lead to gender inequality. Social protection is one of the mechanisms in dealing with conditions of poverty and inadequacy due to environmental problems. The social protection strategy will be better and better suited to the needs of women and men when using a gender perspective. Forms of gender responsive and complementary intervention will support community empowerment, in particular women's empowerment is related to the roles and responsibilities of women in ensuring the survival of their families. The application of social protection with a gender responsive approach can also support the independence of women.

To improve the ability of communities to adapt to the impacts of climate change, both in villages and in cities requires support to deal with risks through adjustments to social protection implementation. Because basically there are limitations of government capacity $[1,2]$. The purpose of this study is to describe the environmental management strategy using gender and life cycle approach through social protection activities.

\section{Conceptual framework}

This study discusses the relationship between environmental management to achieve environmental sustainability through social protection with a gender approach and life cycle for the establishment of more sustainable strategies. Determination of strategies requires decision making that takes into account justice for all communities to shape the independence and resilience of their communities.

The concept of sustainable development includes three aspects which consist of environmental sustainability, social sustainability, and economic sustainability. These three aspects are mutually integrated and their achievements are related to the ability of the development agency. Related to the concept of sustainability, the limits of environmental sustainability as a condition of balance, resilience, and linkages that allow human society to fulfill their needs without exceeding the capacity of the supporting ecosystem to continue to regenerate and fulfill needs by not reducing biodiversity. So in general environmental sustainability focuses on human and ecosystem welfare, related to the existence of ecosystem service mechanisms. [3]. Then social sustainability as a positive condition in the community with the occurrence of equitable access and equality that supports the occurrence of participation with a sense of ownership with a system that transmits awareness to realize sustainability of social actions [4]. While on economic sustainability focuses on the need for economic activities that do not burden future generations, by implementing proportionally through the use of environmental assets and conservation to 
ensure sustainability. Economic sustainability minimizes social costs in meeting standards to protect the environment $[5,6]$.

As an approach to environmental management, a life cycle approach based on Life Cycle Assessment (LCA) is very important for sustainable consumption and production for sustainable development. This approach includes evaluating the environmental impact of a product system through all stages of its life cycle including the environmental, social and economic impacts of a product throughout its entire life cycle. In the LCA, the target is to reduce the use and emission of product resources to the environment and improve their socioeconomic performance throughout their life cycle. This is important for environmental management in sustainable development. In addition, LCA can assist in the development of public policies and strategy design decisions [7]. The life cycle approach can be used to identify conditions regarding the existence of opportunities and risks from an innovation, product or technology, starting from the beginning to the end use, based on the existence of a qualitative process related to thought until an assessment of the life cycle.

The life cycle is related to the process of achieving individual independence and ability so that it has a correlation with gender aspects. Community welfare is closely related to gender equality, because resources such as social, material and economic resource control, and education are strongly influenced by gender equality [8]. Women's empowerment is an effort to achieve gender equality by giving women access to resources and eliminating gender inequality [9]. Program development with a gender responsive approach is very important in environmental management and development planning. Education for women will increase the ability of participation and independence in managing a more sustainable environment [10].

So in the context of efforts to achieve sustainability in environmental management can be through the existence of social protection with a life cycle and gender approach in its realization. Social protection refers to public action in response to the level of vulnerability, risk, and deprivation that is considered socially unacceptable in a particular government or community [11]. Transformative measures in social protection activities to address problems of social inequality and exclusion, such as collective action for workers' rights, or upholding human rights for ethnic minority groups. "Transformative" social protection not only provides financial assistance (emphasis on economic aspects), but also empowers economic, social and cultural rights, so as not to limit the scope of social protection only to increase income and consumption transfers [12]. The context from the social, political and economic aspects also determines the risk of livelihood, in addition to the conditions of existence natural disasters because of the contribution of humans as development agents should be considered [13].

\section{Material and method}

This paper adopts the AHP (Analytical Hierarchy Process) method to determine the environmental strategy based on gender and life cycle approach. The Analytic Hierarchy Process (AHP) was initiated by Thomas L. Saaty [14]. He illustrated AHP as a multicriteria decision-making approach in which factors are organized in a hierarchic structure. Determination of preferred proposal analyzed by doing a pairwise comparison for three levels hierarchy. The first level or top level of hierarchy stands for the objective to propose a model for the environmental management strategy. The criterion as placed at the second level consist of four aspects: human life and economic value, value of nature and life support function, equality and human dignity, and cultural values and indigenous knowledge. There are three strategies proposed on the bottom level to be considered as the alternatives which are empowering of human productivity, conservation of indigenous (local) resources, and the last strategy is implementing social insurance. Then, those 
elements in every levels are weighed and the final score of each preferred proposal is based on judgment from experts and study from relevant works of literature. The hierarchy model of the environmental management proposal is illustrated in Figure 1 below.

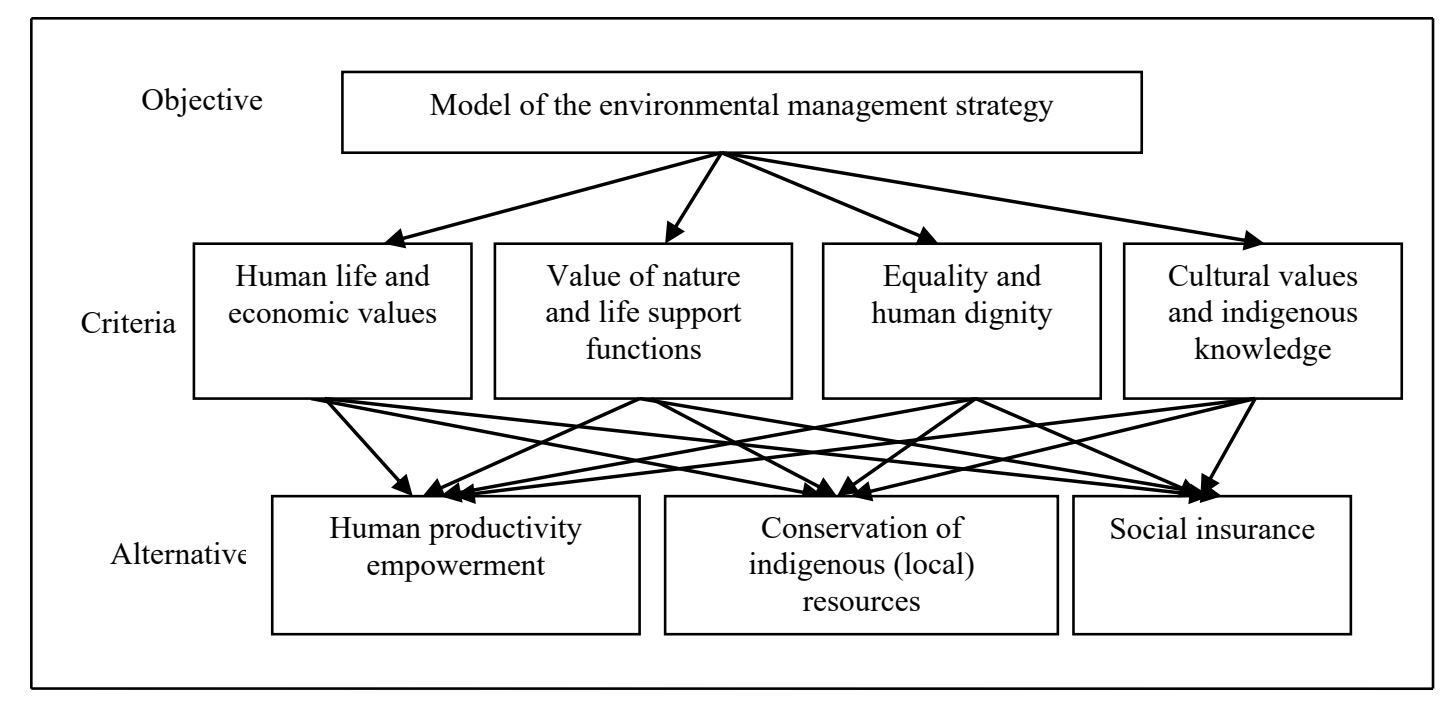

Fig 1. AHP decision model for the environmental management strategy.

Furthermore, the AHP method used 1 to 9 scale to describe the importance level of criteria or alternatives. Table 1 shows the definition of the 1-9 scale using in this decision making.

Table 1. Scale definition in AHP method [15].

\begin{tabular}{|c|c|}
\hline $\begin{array}{l}\text { Intensity of } \\
\text { Importance }\end{array}$ & Definition \\
\hline 1 & The importance scale of criteria/alternative $\mathrm{A}$ and $\mathrm{B}$ are equal \\
\hline 3 & The importance of criteria/alternative $\mathrm{A}$ is moderate than $\mathrm{B}$ \\
\hline 5 & The importance of criteria/alternative $\mathrm{A}$ is stronger than $\mathrm{B}$ \\
\hline 7 & The importance of criteria/alternative $\mathrm{A}$ is very stronger or demonstrated than $\mathrm{B}$ \\
\hline 9 & The criteria/alternative $\mathrm{A}$ is extremely important than $\mathrm{B}$ \\
\hline Reciprocals of above & $\begin{array}{l}\text { If activity } i \text { has one of the above non-zero numbers assigned to it when compared } \\
\text { with activity } j \text {, then } j \text { has the reciprocal value when compared } \\
\text { with } i\end{array}$ \\
\hline
\end{tabular}

Since the process of the AHP method deals with the subjective judgment and may engages too much inconsistency, Saaty determined to a parameter of consistency. The result is categorized as consistent if Consistency Ratio (CR) is less than or equal to 0,10 [15].

\section{Result and discusion}

This study attempts to conduct pairwise comparison to weigh the most important criteria for develop a model of the environmental management strategy. 
Table 2. Matrix of pairwise comparison between objective with respect to the criterion.

\begin{tabular}{|c|c|c|c|c|c|c|}
\hline & HE & VL & EH & CV & Normal & Ranks \\
\hline HE & 1 & 5 & 0.333 & 3 & 0.2622 & 2 \\
\hline VL & 0.200 & 1 & 0.143 & 0.333 & 0.0553 & 4 \\
\hline EH & 3 & 7 & 1 & 5 & 0.5650 & 1 \\
\hline CV & 0.333 & 3 & 0.200 & 1 & 0.1175 & 3 \\
\hline Consistency Ratio & \multicolumn{7}{|c|}{0.0438} \\
\hline
\end{tabular}

Notes: $\mathrm{HE}=\mathrm{Human}$ life and economic values; $\mathrm{VL}=$ Value of nature and life support functions;

$\mathrm{EH}=$ Equality and human dignity; $\mathrm{CV}=\mathrm{Cultural}$ values and indigenous knowledge

After synthesizing the judgment from expert and literature review, table 2 shows the result of comparison between objective and criteria. Not surprisingly, the calculation emphasizes more on equality and human dignity $(56.50 \%)$ because the proposal to develop environmental management strategy is in line with the concept of social protection with a community-based approach. The approach provides an opportunity to improve the community's ability to achieve environmental resilience. The social protection will also increase people's access to environmental resources so that people are able to participate in environmental management. Gender equality decreases the imbalanced power between male and female and works as key root to community. Besides, the equality of gender needs to be top priority in the plans and policies to pursue the environmental and economic sustainability [16]. The strategy will earn the most important values if the implemented program provides more opportunities for women to contribute in all aspects of environmental management. The values of human life and economic criteria considered as the second important factor by $26.22 \%$.

Table 3. Pairwise comparison matrix between the criteria of human life and economic values and value of nature and life supports to the alternatives.

\begin{tabular}{|c|c|c|c|c|c|c|c|c|c|c|}
\hline & \multicolumn{9}{|c|}{ Human life and economic values } & \multicolumn{5}{c|}{ Value of nature and life supports } \\
\hline & HPE & CIR & SI & $\begin{array}{c}\text { Norma } \\
\mathbf{l}\end{array}$ & $\begin{array}{c}\text { Rank } \\
\text { s }\end{array}$ & HPE & CIR & SI & $\begin{array}{c}\text { Norma } \\
\text { I }\end{array}$ & $\begin{array}{c}\text { Rank } \\
\text { s }\end{array}$ \\
\hline HPE & 1 & 5 & 3 & 0.637 & 1 & 1 & 7 & 3 & 0.667 & 1 \\
\hline CIR & 0.200 & 1 & 0.333 & 0.105 & 3 & 0.143 & 1 & $\begin{array}{c}0.33 \\
3\end{array}$ & 0.088 & 3 \\
\hline SI & 0.333 & 3 & 1 & 0.258 & 2 & 0.333 & 3 & 1 & 0.243 & 2 \\
\hline $\begin{array}{l}\text { Consistency } \\
\text { Ratio }\end{array}$ & \multicolumn{3}{|c|}{0.037} \\
\hline
\end{tabular}

Notes: HPE $=$ Human productivity empowerment; $\mathrm{CIR}=$ conservation of indigenous resources; $\mathrm{SI}=$ social insurance

From the result of pairwise comparison analysis between between the criteria of human life and economic values and value of nature and life supports to the alternatives showed in Table 3, it was found that all of the comparisons are consistent as Consistency Ratio is lower than 0.10 (each 0.037 and 0.007 ). For human life and economic values criteria, the strategy to empowering human productivity is the priority $(0.637)$, followed by implementation of social insurance scheme $(0.258)$ and conservation of indigenous resources $(0.105)$. 
Meanwhile, in the analysis that based on value of nature and life supports criteria, the priority results are remain the same with previous criteria, respectively are human productivity empowerment program (0.667), implementation of social insurance $(0.243)$ and conservation of indigenous resources (0.088).

Table 4. Pairwise comparison matrix between the criteria of equality and human dignity and cultural values and indigenous knowledge to the alternatives.

\begin{tabular}{|c|c|c|c|c|c|c|c|c|c|c|}
\hline & \multicolumn{9}{|c|}{ Equality and human dignity } & \multicolumn{3}{c|}{ Cultural values and indigenous knowledge } \\
\hline & HPE & CIR & SI & Normal & Ranks & HPE & CIR & SI & Normal & Ranks \\
\hline HPE & 1 & 7 & 5 & 0.731 & 1 & 1 & 5 & 3 & 0.627 & 1 \\
\hline CIR & 0.143 & 1 & 0.333 & 0.081 & 3 & 0.200 & 1 & 0.250 & 0.094 & 3 \\
\hline SI & 0.200 & 3 & 1 & 0.188 & 2 & 0.333 & 4 & 1 & 0.279 & 2 \\
\hline $\begin{array}{l}\text { Consistenc } \\
\text { y Ratio }\end{array}$ & \multicolumn{9}{|c|}{0.062} & \multicolumn{7}{|c|}{0.083} \\
\hline
\end{tabular}

Notes: $\mathrm{HPE}=$ Human productivity empowerment; $\mathrm{CIR}=$ conservation of indigenous resources; $\mathrm{SI}=$ social insurance

Table 4 described the results of two pair-wise comparisons between equality and human dignity and cultural values and indigenous knowledge criteria to the alternatives. In the related criteria, the option of human productivity empowerment is the most preferred strategy to implement in the proposal of environmental management by 0.731 and 0.627 .

Table 5. Summary of the AHP method.

\begin{tabular}{|c|c|c|c|}
\hline Alternatives & Total & Normal & Ranks \\
\hline HPE & 0.3452 & 0.6905 & 1 \\
\hline CIR & 0.0445 & 0.0891 & 3 \\
\hline SI & 0.1102 & 0.2204 & 2 \\
\hline
\end{tabular}

Table 5 has provided a final calculation of the AHP approach to propose a model of the environmental management strategy. The analysis shows that facilitating program related to human productivity empowerment is a priority based on the AHP method (0.6905). The result of this research shows that the strategy to empower human productivity is the most essential concept to emphasize the program achievement.

In social protection activities a strong synergy is needed between economic strengthening (including protection, prevention, promotive) and strengthening the role of social protection through transformative strategies. The possibility of social risk and vulnerability causes the importance of empowering the poor or marginalized groups by applying gender responsive approaches. Empowerment through social protection by increasing awareness and developing community capacity, both regarding information on climate change impacts and gender issues so that there is an increase in the productivity of the community, especially women. Empowerment also requires the support of access and facilities for contributions that citizens cope with the effects of climate change. Education and information material must be gender sensitive for capacity building and gender responsive cross-sectoral training. In addition, the existence of a gender approach and life cycle in environmental management strategies through social protection through transformative programs will increase equal participation between women and men in planning, decision making and implementation of environmental management strategies.

Strategies to increase human productivity will direct the community to be able to manage natural resources, facilitate revenue, and improve the welfare of the community. So this strategy can support social justice as the key to the implementation of sustainable 
development. The realization of this social protection strategy in environmental management requires the existence of partnerships between the community and various stakeholders. Because efforts to increase human productivity in environmental management and the use of natural resources require the existence of a control mechanism and a framework that applies standards to its social protection programs.

\section{Conclusion}

For sustainable development in the face of the impacts of climate change requires an environmental management strategy with a gender approach and life cycle. Implementation of the strategy through empowering human productivity, especially for women with gender equality and social justice. Environmental planning and management policies also need to be formulated in an integrated manner and pay attention to basic needs according to gender. The results of this study show that social protection with gender mainstreaming will increase the ability of citizens to participate and strengthen communities in managing the urban environment that achieve social justice for the community for the sustainability of the city. The contribution of this study can be an alternative strategy for environmental management in the city and more gender responsive policy making. Then, the recommendation from this study is that there is a need for a planning mechanism of transformative social protection strategies that are applied in an integrated and holistic manner for the purpose of positive social protection in order to contribute to the fundamental policy objectives of the pro-marginalized groups and increase social justice.

\section{Acknowledgements}

Thank you for research funding support from the Ministry of Research, Technology and Higher Education (Kemristekdikti) with the Higher Education Basic Research Program in 2018, Directorate of Research and Community Service, University of Indonesia

\section{References}

1. A. Barrientos, S. Hickey, D. Hulme, M. Nin, M. World Development 40,1 (2012)

2. K. Subbarao, C. del Ninno, C. Andrews, C. Rodríguez-Alas. Public Works as a Safety Net, Design, Evidence, and Implementation (The World Bank, Washington DC, 2013)

3. J. Morelli, J. of Env.Sustain. 1: Iss. 1, 2 (2011)

4. S. McKenzie. Social Sustainability: Towards Some Definitions (Hawke Research Institute Working Paper Series 27, 2004)

5. A. Markulev, A. Long. On sustainability: an economic approach. Staff Research Note. Productivity Commission, Canberra (2013)

6. OECD (Organisation for Economic Co-operation and Development). OECD Better Life Index (2012)

7. C. Koroneos, E. Nanaki, D. Rovas, M. Krokida. Life Cycle Assessment: A Strategic Tool for Sustainable Development Decisions (2013)

8. N. Kabeer, Gender \& Development 13,1 (2005)

9. L. Mayoux, M. Hartl. Gender and rural microfinance: Reaching and empowering women (International Fund For agricultural Development (IFAD), Powerguda India, 2009)

10. D. Asteria, Budidarmono, H. Herdiansyah' N. L. Ni'mah. IOP Conference Series: Earth and Environmental Science 126, 1 (2018) 
11. A. Norton, T. Conway, M. Foster, M. Social protection concepts and approaches: implications for policy and practice in international development (Working Paper 143, Centre for Aid and Public Expenditure, Overseas Development Institute (ODI), London, 2000)

12. S. Devereux, R. Sabates-Wheeler. Transformative social protection (IDS Working Paper 232, Institute of Development Srudies. Brighton, England, 2004)

13. G. Bankoff, G. Frerks, D. Hilhorst (eds) Mapping Vulnerability: Disasters, Development and People (Earthscan, London, 2004)

14. Y. Wind, T.L Saaty, T.L. Management Science 26, 641-658 (1980)

15. T.L Saaty. What Is the Analytic Hierarchy Process? (Springer, Berlin,1998)

16. C. Chan, M. Audi, A. Ali, Amjad. The Impact of Gender Inequality and Environmental Degradation on Human Well-Being in The Case of Pakistan: A Time Series Analysis (MPRA Paper, 2017) 